\title{
Acompanhamento de Pré-escolares Agressivos: Adaptação na Escola e Relação Professor-Aluno
}

A long term study of preschoolers with aggressive behavior:
School adjustment and teacher-student relationship

Acompañamiento de preescolares agresivos: Adaptación en la escuela y relación maestro-alumno
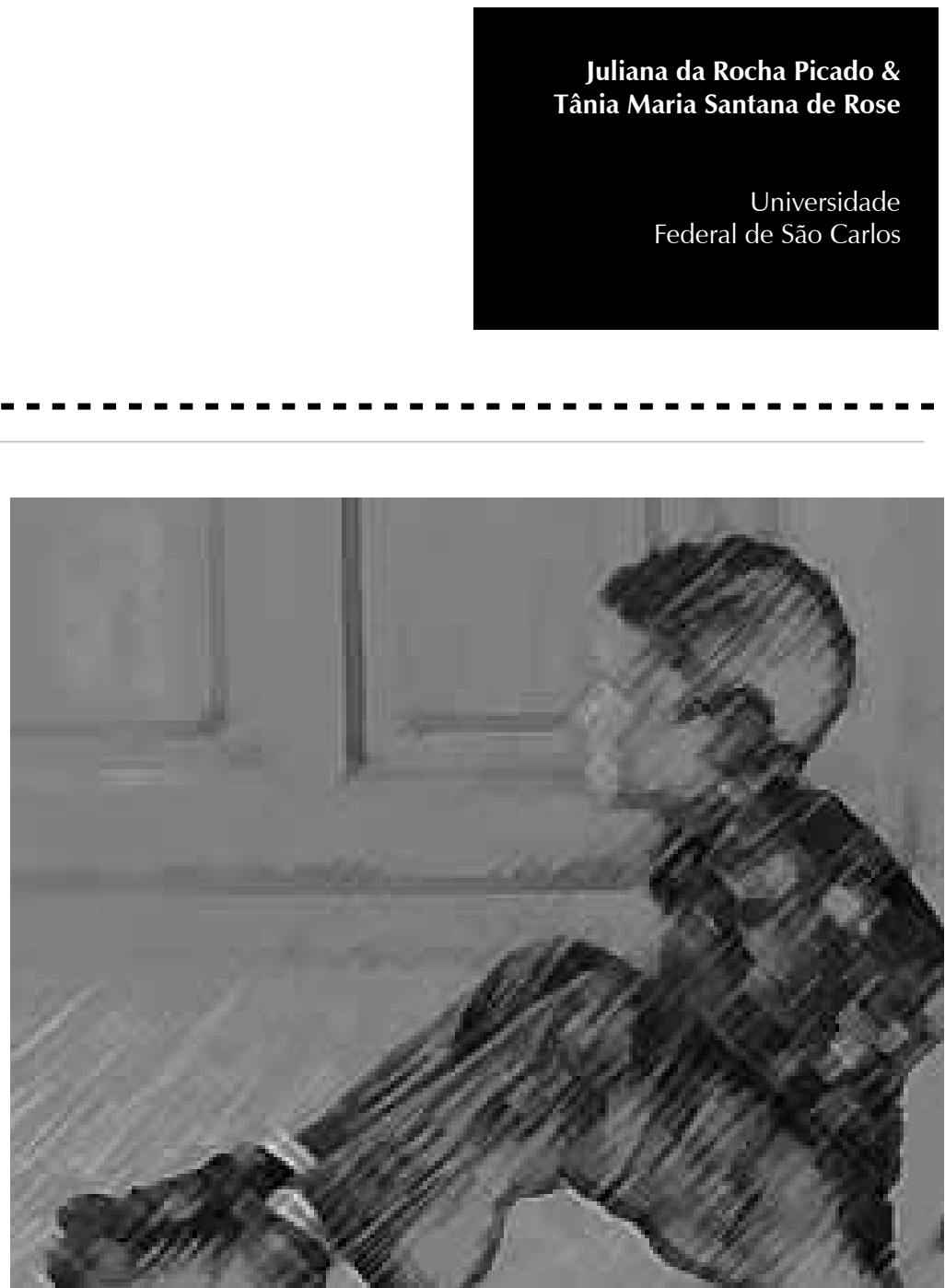
Resumo: O estudo teve como objetivos: 1) verificar problemas de comportamento e aproveitamento acadêmico em um grupo de 11 alunos na fase final da pré-escola que foram indicados como agressivos no início da mesma; 2) avaliar a qualidade da relação professor-aluno da amostra. Instrumentos utilizados: TRF - teacher's report form, entrevista sobre desempenho acadêmico e adaptação escolar e entrevista sobre qualidade da relação professor-aluno. Os resultados mostram que 63,5\% dos alunos apresentam de um a quatro problemas externalizantes e/ou internalizantes. Os altos índices de comportamentos agressivos permanecem entre 45\% dos alunos. Apenas 2 das 11 relações professor-aluno estudadas apresentam em alto grau os elementos positivos avaliados pela entrevista. Conclui-se que a maioria das crianças está exposta a fatores de risco, sem evidências claras de rede protetora suficiente para minimizar tais efeitos. Discute-se a possível trajetória a ser seguida pelas crianças e as possibilidades de ações em conjunto que poderiam reverter esse quadro.

Palavras-chave: Estudo de acompanhamento. Pré-escolares. Agressividade. Relação professor-aluno.

Abstract: The objectives of this paper were: 1) check behavior problems and school performance of 11 students in the end of preschool that presented high rates of aggressive behavior in the beginning of this phase; 2) evaluate the quality of the teacher-student relationships. Instruments: teacher's report form - TRF, academic skills and adaptation interview and teacher's relationship interview. The results show that $63.5 \%$ of preschoolers have one to four externalizing and/or internalizing problems. The high rates of aggressive behavior remain in $45 \%$ of the students. Only 2 out of 11 teachers presented the positive elements proposed in the interview. Most of these children are exposed to risk factors, and it doesn't seem they have enough protective factors to minimize these effects. Possible aggressive pathways to be followed by these children are discussed as actions that could change this situation.

Keywords: Long term study. Preschoolers. Aggressiveness. Teacher-student relationship.

Resumen: El estudio tuvo como objetivos: 1) verificar problemas de comportamiento y aprovechamiento académico en un grupo de 11 alumnos en la fase final de la pre-escuela que fueron indicados como agresivos en el inicio de la misma; 2) evaluar la calidad de la relación maestro-alumno de la muestra. Instrumentos utilizados: TRF - teacher's report form, entrevista sobre desempeño académico y adaptación escolar y entrevista sobre calidad de la relación maestro-alumno. Los resultados muestran que 63,5\% de los alumnos presentan de uno a cuatro problemas externalizantes y/o internalizantes. Los altos índices de comportamientos agresivos permanecen entre 45\% de los alumnos. Apenas 2 de las 11 relaciones maestroalumno estudiadas presentan en alto grado los elementos positivos evaluados por la entrevista. Se concluye que la mayoría de los niños están expuestos a factores de riesgo, sin evidencias claras de red protectora suficiente para minimizar tales efectos. Se discute la posible trayectoria a ser seguida por los niños y las posibilidades de acciones en conjunto que podrían revertir ese cuadro.

Palabras clave: Estudio de acompañamiento. Preescolares. Agresividad. Relación maestro-alumno.

Nos últimos anos, verifica-se nas escolas uma crescente preocupação quanto às manifestações de agressividade e violência apresentadas por alunos de diferentes níveis de ensino. Os professores queixamse do aumento de comportamentos antisociais, comportamentos agressivos, atitudes desafiadoras, desobediência, hiperatividade, não concentração nas tarefas e ausência de auto-regulação por parte dos alunos. Eles também manifestam ter dificuldades para lidar de forma efetiva com esses tipos de comportamentos e atitudes dos alunos (Del Prette \& Del Prette, 2001; Gomide, 2001, 2003; López, 2004; Marinho, 2003).
Muitos professores atribuem a variáveis familiares a responsabilidade pela aquisição e manutenção dos comportamentos agressivos dos alunos bem como consideram que pouco pode ser feito no âmbito da escola em relação à agressividade (Pianta, 1998). No entanto, observa-se um descompasso entre o que profissionais das escolas pensam e as implicações educacionais decorrentes dos estudos sobre comportamentos agressivos na primeira infância.

Os estudos sobre o desenvolvimento de comportamentos agressivos têm evidenciado a importância da distinção entre manifestações 
A necessidade de identificação precoce de alunos que apresentam altos índices de agressão apresenta-se como uma das condições básicas para intervenções dirigidas que visam a alterar a trajetória de risco psicossocial desses alunos (Tremblay, 2000). agressivas transitórias e manifestações estáveis. Alunos de todas as idades ocasionalmente recorrem a comportamentos agressivos para resolver conflitos interpessoais e enfrentar situações estressantes. No entanto, existem alunos que desde a pré-escola apresentam, de forma consistente e intensa, condutas agressivas, manifestações de raiva, irritabilidade, comportamentos desafiadores, de birra, insultos, ameaças, condutas violentas e recusa à obediência. Em geral, as crianças agressivas não só representam uma ameaça para os seus colegas e professores mas também se colocam em situação de perigo. Esse tipo de agressividade implica, em geral, o aparecimento de sérias dificuldades de relacionamento entre os alunos e seus pais, colegas e professores (Coie \& Dodge, 1998).

Comportamentos agressivos são mais freqüentes em meninos. Essa diferença de gênero é encontrada em estudos efetuados em diferentes localidades e populações (Tremblay, 2000).

Atualmente, há um reconhecimento dos avanços quanto ao entendimento da trajetória de desenvolvimento do comportamento agressivo, compreensão das origens e da evolução da agressão. Evidencia-se uma associação entre agressão na primeira infância e comprometimentos do ajustamento social nos períodos posteriores da vida, incluindo violência e delinqüência na idade adulta. Os comportamentos agressivos tendem a persistir ao longo do tempo, e os estudos longitudinais descrevem o desenvolvimento e as alterações nas formas de agressão, desde a mais tenra infância até a adolescência. São intensificadas as mentiras, brigas, lutas na infância, crueldade com os animais, vandalismo e comportamentos criminosos na adolescência (Coie \& Dodge, 1998; Patterson, Debarishe, \& Ramsey, 1989; Patterson, Reid, \& Dishion, 2002).

Verifica-se que as crianças que apresentam altos índices de comportamento agressivo na primeira infância têm maior probabilidade de apresentar comprometimentos no ajustamento escolar. Esses alunos têm maiores riscos de obter resultados acadêmicos insatisfatórios, de ser rejeitados pelos colegas e professores, têm mais possibilidade de desistir da escola e de ser indicados para os serviços de educação especial e de saúde mental (Patterson et al., 2002; Pianta \& Walsh, 1996).

Esses resultados sobre a estabilidade dos comportamentos agressivos e das conseqüências para outras áreas da vida das crianças têm implicações para a definição de condições relevantes tendo em vista um trabalho preventivo no contexto escolar. A necessidade de identificação precoce de alunos que apresentam altos índices de agressão apresenta-se como uma das condições básicas para intervenções dirigidas que visam a alterar a trajetória de risco psicossocial desses alunos (Tremblay, 2000).

Os trabalhos recentes com alunos que apresentam dificuldades comportamentais e de ordem disciplinar destacam as contribuições advindas dos estudos que investigam as relações entre as características interpessoais do ambiente escolar (relação professor-aluno, relação aluno-aluno e relação aluno-escola) e o ajustamento acadêmico e socioemocional dos alunos. Os estudos sobre as características da relação professor-aluno norteados por essa perspectiva têm utilizado os construtos-chave derivados da literatura sobre apego criançaspais (segurança, ambivalência, resistência) para definirem as qualidades/dimensões dessa relação e verificarem as suas implicações (Birch \& Ladd, 1997).

Pianta e Steinberg (1992) identificaram a proximidade/intimidade (afeto/carinho e comunicação aberta), a dependência e o conflito como três aspectos qualitativamente importantes e distintos da relação professoraluno. Os estudos com base nessa perspectiva têm sugerido que interações responsivas e 
positivas contribuem para o ajustamento acadêmico e social dos alunos (Birch \& Ladd, 1997; Hamre \& Pianta, 2005; Pianta, 1998).

Há um forte reconhecimento da importância de os professores criarem em sala de aula um ambiente carinhoso e seguro para seus alunos. Estudos como o de Hamre e Pianta (2005) têm fornecido evidências de que, para crianças em situação de risco, contar com um professor caloroso e apoiador parece ser crítico para auxiliá-las a desenvolverem-se adequadamente. Esses pesquisadores fizeram comparações entre duas amostras, sendo a primeira composta por alunos de 1ạ série em situação de alto risco que freqüentavam salas de aula conduzidas por professores que forneciam apoio emocional regularmente ao longo das interações diárias, e a segunda formada por um grupo de alunos que estavam em classes menos apoiadoras. Eles verificaram que, ao final da 1a série, os alunos que estavam em salas de aula mais apoiadoras demonstraram melhor aproveitamento e menos conflito com os professores. Esse tipo de apoio do professor, mesmo sendo fornecido na 1aㅡ série, parece ter implicações para o comportamento e ajustamento do aluno em momentos posteriores.

Pianta (1998) argumenta que a relação entre professores e alunos pode funcionar como um fator de proteção, contribuindo para a minimização dos fatores de risco aos quais as crianças estão expostas. Experiências como essas podem capacitar uma criança a construir relacionamentos que compensariam aqueles estabelecidos com outros adultos, especialmente com os pais, promovendo interações que incentivam a melhora de suas performances em sala de aula e recuperam a auto-estima da criança.

Os estudos vêm mostrando como os professores podem influenciar de forma positiva a trajetória de desenvolvimento de crianças com risco psicossocial, facilitando a adaptação das mesmas na escola. Especificamente, o papel do professor como fator protetivo tem sido evidenciado através do contato próximo entre este e o aluno, da pouca discórdia entre eles, das expectativas otimistas de um para com o outro e do cuidado do professor para com o aluno (Birch \& Ladd, 1997). Os resultados das pesquisas indicam que estudantes com comportamentos agressivos podem se beneficiar de relacionamentos com professores que demonstram compreendêlos, que encorajam a comunicação e a expressão de emoções (Pianta, 1998).

Considerando a importância da identificação precoce de alunos que apresentam comportamentos agressivos e de estudos que possibilitem o acompanhamento do desenvolvimento e ajustamento desses alunos no contexto escolar bem como a importância da realização de estudos que descrevam dimensões relevantes da relação professoraluno associadas ao apoio emocional e afetivo dado aos alunos, pretendeu-se, no presente trabalho, realizar um estudo de acompanhamento dos alunos que estavam na fase final da pré-escola, e que, no início desta, já haviam sido indicados pelos professores por apresentar altos índices de desobediência, agressão física e agressão verbal. Esses alunos foram participantes do estudo de Luizzi e De Rose (2003), que avaliou crianças indicadas pelas professoras como agressivas no início da pré-escola. Essa pesquisa anterior evidenciou 55 crianças pré-escolares que apresentavam comportamentos agressivos de alta freqüência e intensidade em escolas municipais de ensino infantil de uma cidade do interior de São Paulo. Os dados foram fornecidos pelas respectivas professoras das crianças, que preencheram um questionário enviado a todas as escolas de ensino infantil do Município com questões sobre a existência ou não de crianças agressivas, sua identificação e solicitação das descrições dos comportamentos considerados agressivos. Dentre os resultados, destaca- 
se que a maioria das crianças era do sexo masculino (80\%), e que a agressão física era a predominante.

A presente pesquisa buscou dar continuidade a esse trabalho através de uma avaliação feita em 11 daquelas 17 crianças, que, após passados dois anos, ainda freqüentavam a pré-escola.

Dada a importância do apoio socioemocional e afetivo oferecido por professores para alunos de risco, o presente estudo procurou focalizar a qualidade da relação professoraluno da amostra.

\section{Objetivos}

1) Verificar a existência de problemas de comportamento e características do aproveitamento acadêmico em um grupo de 11 alunos na fase final da pré-escola que foram indicados como agressivos no início da mesma.

2) Avaliar a qualidade da relação estabelecida entre professores e alunos participantes, segundo as categorias propostas pela entrevista da qualidade da relação professoraluno, de Pianta (1998).

\section{Método}

\section{Participantes}

Participaram do estudo 11 alunos e seus respectivos professores de 8 escolas municipais de ensino infantil (EMEIs) da rede pública de uma cidade de médio porte do interior de São Paulo.

Dentre os alunos, 9 eram do sexo masculino e 2 do sexo feminino, as idades variavam de 6 a 7 anos e 3 meses, e a maioria estava na fase final da pré-escola. Esses alunos, quando tinham idades entre 4 e 5 anos e três meses, foram indicados pelos professores como crianças que apresentavam altos índices de comportamentos agressivos.

Das 11 crianças participantes, a n. 1 e a n. 3 estão sob a responsabilidade da mesma professora, e as crianças 4 e 6 também estudam com apenas uma professora. Dessa maneira, este estudo tem como participantes 11 crianças e seus respectivos 9 professores, que forneceram informações sobre seus alunos e sobre a relação estabelecida entre eles.

\section{Instrumentos}

Inventário de Comportamentos da Infância e Adolescência - Versão do Professor. Teacher's Report Form (TRF) (Achenbach, 1991), traduzido por Luizzi e De Rose (2003).

É composto por duas partes, contendo a primeira questões sobre a identificação da criança e sobre seu desempenho escolar, e a segunda parte é constituída por 113 itens relativos à avaliação dos problemas de comportamento. Cada um desses itens é classificado pelo professor de acordo com uma escala que varia de 0 a 2 pontos: recebem 0 aqueles itens considerados falsos, 1 aqueles relativamente verdadeiros e 2, os verdadeiros. Os itens são referentes a problemas que se distribuem em 8 escalas: 1) introversão/retraimento; 2) queixas somáticas; 3) ansiedade/depressão; 4) problemas sociais; 5) problemas de pensamento; 6) problemas de atenção; 7) comportamento de violação de regras e 8) comportamento agressivo. A soma dos itens das escalas pode indicar problemas internalizantes e externalizantes que, somados, resultam na escala de problemas totais. Uma versão eletrônica para a análise dos pontos do TRF possibilita a conversão dos pontos e indica a necessidade de atendimento clínico da criança avaliada.

Entrevista sobre desempenho acadêmico e adaptação escolar (De Rose, Coser, \& Togumi, 2004). 
Consiste em entrevista semi-estruturada com um roteiro elaborado para a obtenção de informações acerca das percepções dos professores sobre as queixas escolares e sobre a adaptação do aluno na escola. Os professores são solicitados a relatar o desempenho acadêmico do aluno, a relação do aluno com os colegas, a motivação para atividades, a independência para a realização das atividades e o comportamento em sala de aula.

Entrevista de avaliação da qualidade da relação professor-aluno (Pianta, 1998)

Utilizou-se a tradução da Teacher Relationship Interview (TRI) (Pianta, 1998), que possibilita que professores forneçam informações sobre oito dimensões da relação professor-aluno e viabiliza a identificação do nível de apoio socioemocional e afetivo fornecido pelo professor a um determinado aluno.

Solicita-se que o professor relate experiências positivas e negativas vivenciadas com o aluno em questões relacionadas à disciplina, socialização, intencionalidade, eficácia de ensino e afeto mútuo, que relate suas percepções sobre os seus sentimentos e os do aluno sobre essas experiências e percepções de como ambos se comunicam em relação à necessidade de independência ou de ajuda. Além disso, existem três questões sobre o relacionamento do professor com outros adultos na época em que era criança.

As respostas dadas pelos professores foram analisadas de acordo com o Manual de Codificação do TRI (Pianta, 1998), que apresenta os critérios qualitativos com base nos quais é dada a pontuação que varia de 1 a 7 para cada uma das oito dimensões. Recebem pontuações altas (6 e 7) os professores que fornecem evidências da presença do construto e exemplos desse construto de forma consistente. As pontuações médias ( 3 a 5 ) indicam uma apresentação mista do construto e as baixas pontuações ( 1 e 2 ) indicam escassa ou nenhuma evidência da presença deste.

As respostas foram avaliadas em função dos critérios estabelecidos para cada uma das oito dimensões: 1) sensibilidade para disciplina: avalia as maneiras de lidar com comportamentos do aluno em sala de aula e formas pró-ativas de interação; 2) função como base segura: avalia o apoio emocional, a confiança e o encorajamento fornecidos ao aluno e quão isso se relaciona com as competências do mesmo; 3) visão da perspectiva do aluno: avalia o conhecimento do professor sobre estados internos dos alunos e sua capacidade de se colocar no lugar deste; 4) senso de eficácia: avalia o sentimento de efetividade do professor; 5) expressão de afeto positivo: avalia expressões de sentimentos tais como satisfação, alegria, proximidade, orgulho, carinho; 6) neutralização /negação do afeto negativo: avalia as tentativas de ocultar os sentimentos negativos na relação; 7) sentimento de desamparo/ ineficácia: avalia os sentimentos de ineficácia do professor em relação a sua atuação; 8 ) expressão de raiva ou hostilidade: avalia o quanto é explícita e consistente essa expressão.

\section{Procedimento de coleta e análise dos dados}

Os dados foram coletados nas dependências das escolas e sob a responsabilidade da pesquisadora. Todos os participantes leram e assinaram um Termo de Consentimento Livre e Esclarecido. Para a aplicação dos instrumentos, foram utilizados, em média, três encontros com professores, com duração média de 45 minutos cada. Inicialmente, aplicou-se a entrevista sobre desempenho acadêmico e adaptação escolar, em seguida a entrevista sobre a relação professor- aluno e, por fim, o TRF.

A análise dos dados do TRF foi viabilizada pelo programa computadorizado, que converteu 
os pontos e apresentou as indicações internalizantes, externalizantes e totais para cada um dos participantes. Em seguida, procurou-se comparar as descrições obtidas no estudo anterior (Luizzi \& De Rose, 2003) com as fornecidas na entrevista sobre desempenho acadêmico e adaptação escolar e com as indicações provindas do TRF. Efetuou-se uma análise do conteúdo dos relatos, a fim de viabilizar a categorização das respostas.

As respostas obtidas nas duas entrevistas foram analisadas por dois codificadores independentes, que discutiram em reuniões algumas divergências de pontuação e chegaram a um acordo em todas elas.

\section{Resultados}

Na Tabela 1, são apresentados os resultados relativos às indicações de queixas feitas pelas professoras atualmente, às classificações limítrofe e clínica para as oito categorias de problemas obtidos pelo TRF, características do desempenho acadêmico e adaptação escolar dos alunos.

Tabela 1. Queixas de professoras, classificações do TRF, desempenho e adaptação escolar.

\begin{tabular}{|c|c|c|c|c|c|}
\hline \multirow[t]{2}{*}{ Aluno } & \multirow{2}{*}{$\begin{array}{l}\text { Problemas } \\
\text { atuais de } \\
\text { comportamento } \\
\text { segundo } \\
\text { professoras }\end{array}$} & \multirow{2}{*}{$\begin{array}{l}\text { Classificações de } \\
\text { problemas de } \\
\text { comportamentos } \\
\text { obtidos pelo TRF } \\
\text { Limítrofe }\end{array}$} & \multirow{2}{*}{$\begin{array}{l}\text { Classificações de } \\
\text { problemas de } \\
\text { comportamento } \\
\text { obtidos pelo } \\
\text { TRF } \\
\text { Clínica }\end{array}$} & \multicolumn{2}{|c|}{$\begin{array}{l}\text { Características do } \\
\text { desempenho acadêmico e } \\
\text { adaptação escolar }\end{array}$} \\
\hline & & & & $\begin{array}{l}\text { Motivação e } \\
\text { atendimento a } \\
\text { exigências acad. }\end{array}$ & $\begin{array}{l}\text { Relação } \\
\text { com } \\
\text { colegas }\end{array}$ \\
\hline 1 & & & & Satisfação & Satisfação \\
\hline 2 & Agressividade & & & Satisfação & Insatisfação \\
\hline 3 & Hiperatividade & & & Satisfação & Insatisfação \\
\hline 4 & Agressividade & & $\begin{array}{l}\text { comportamento agres- } \\
\text { sivo, violação de regras, } \\
\text { problema pensamento }\end{array}$ & Regular & Insatisfação \\
\hline 5 & & $\begin{array}{l}\text { Introversão e } \\
\text { retraimento }\end{array}$ & $\begin{array}{l}\text { Comportamento } \\
\text { agressivo }\end{array}$ & Satisfação & Insatisfação \\
\hline 6 & Agressividade & $\begin{array}{l}\text { Comportamento } \\
\text { agressivo }\end{array}$ & & Regular & Insatisfação \\
\hline 7 & $\begin{array}{l}\text { Baixa } \\
\text { auto-estima/ } \\
\text { insegurança }\end{array}$ & & $\begin{array}{l}\text { Ansiedade e } \\
\text { depressão, } \\
\text { problema social }\end{array}$ & Insatisfação & Satisfação \\
\hline 8 & Agressividade & $\begin{array}{l}\text { comportamento } \\
\text { agressivo }\end{array}$ & & Satisfação & Insatisfação \\
\hline 9 & Agressividade & & & Satisfação & Insatisfação \\
\hline 10 & $\begin{array}{l}\text { Agressividade/ } \\
\text { baixa auto-estima/ } \\
\text { insegurança }\end{array}$ & & Problema social & Insatisfação & Insatisfação \\
\hline 11 & Agressividade & Problema social & $\begin{array}{l}\text { Problema de aten- } \\
\text { ção, violação de regras, } \\
\text { comportamento agressivo }\end{array}$ & Insatisfação & Insatisfação \\
\hline
\end{tabular}


Observa-se que os alunos 2, 4, 6, 8, 9 e 11 têm a agressividade como a principal queixa indicada. Para o aluno 3, a hiperatividade é a queixa apresentada. Para os alunos 7 e 10, há indicações de baixa auto-estima e insegurança.

Os alunos 1, 2, 3 e 9 receberam classificação não clínica para as oito categorias de comportamentos avaliados pelo TRF. Foram verificadas, para os demais sete alunos, variações quanto ao tipo de classificação (limítrofe e/ou clínica) e ao número de categorias de problemas de comportamentos apresentados, que variam de uma a quatro.

Três alunos apresentaram uma única indicação (limítrofe ou clínica) para uma categoria de problemas de comportamentos. Os alunos 6 e 8 obtiveram classificação limítrofe para o comportamento agressivo, enquanto o aluno 10 obteve classificação clínica para a categoria problema social.

O aluno 5 obteve classificação limítrofe para a categoria introversão/retraimento e classificação clínica para comportamento agressivo. $\mathrm{O}$ aluno 7 apresenta classificação clínica para as categorias ansiedade/depressão e problema social.

Já o aluno 4 obteve classificação clínica para as categorias comportamento agressivo, violação de regras e problemas de pensamento. O aluno 11 obteve classificação limítrofe para problemas sociais e clínica para as categorias de comportamento agressivo, violação de regras e problemas de atenção.

Pode-se observar que $36.3 \%$ da amostra não apresenta problemas comportamentais,
$27.2 \%$ os apresentam em nível limítrofe e 45.4\% em nível clínico.

Em relação ao aproveitamento acadêmico, a apreciação dos professores quanto ao atendimento das exigências acadêmicas características da pré-escola e sobre a motivação para engajamento nas atividades propostas aponta que os alunos 1, 2, 3, 5, 8 e 9 apresentam esses itens de maneira satisfatória. Destaca-se que esses mesmos alunos se relacionam com colegas de maneira insatisfatória, com exceção do aluno 1, que se relaciona satisfatoriamente.

Os alunos 4 e 6 apresentam, segundo a professora, motivação e atendimento das exigências acadêmicas de maneira regular, além de relacionamento insatisfatório com colegas. Já os alunos 10 e 11 apresentam ambas as categorias de maneira insatisfatória, enquanto o aluno 7 não apresenta bom desempenho acadêmico, embora se relacione de maneira satisfatória com os colegas.

A Tabela 2 mostra os escores obtidos pelos professores nas escalas da entrevista sobre a qualidade da relação professor-aluno (Pianta, 1998).

Os resultados da análise qualitativa das respostas referentes às escalas positivas (sensibilidade para disciplina, função como base segura, tomada de perspectiva do aluno, senso de eficácia e expressão do afeto positivo) e das escalas negativas (neutralização do afeto negativo, desamparo e expressão de raiva/ hostilidade) mostram variações nos valores das pontuações obtidas. 
Tabela 2. Escores relativos às oito dimensões da relação professor-aluno.

\begin{tabular}{|c|c|c|c|c|c|c|c|c|c|c|c|}
\hline & $\begin{array}{l}\text { Prof. } \\
\text { A } 7\end{array}$ & $\begin{array}{l}\text { Prof. } \\
\text { A } 8\end{array}$ & $\begin{array}{l}\text { Prof. } \\
\text { A } 2 \\
\end{array}$ & $\begin{array}{l}\text { Prof. } \\
\text { A } 3\end{array}$ & $\begin{array}{l}\text { Prof. } \\
\text { A } 10\end{array}$ & $\begin{array}{l}\text { Prof. } \\
\text { A } 9\end{array}$ & $\begin{array}{l}\text { Prof. } \\
\text { A } 1 \\
\end{array}$ & $\begin{array}{l}\text { Prof. } \\
\text { A } 11 \\
\end{array}$ & $\begin{array}{l}\text { Prof. } \\
\text { A } 6\end{array}$ & $\begin{array}{l}\text { Prof. } \\
\text { A } 5 \\
\end{array}$ & $\begin{array}{l}\text { Prof. } \\
\text { A } 4\end{array}$ \\
\hline $\begin{array}{l}\text { Sensib. } \\
\text { para } \\
\text { disciplina }\end{array}$ & $\begin{array}{l}\text { Alto } \\
\text { (7) }\end{array}$ & $\begin{array}{l}\text { Alto } \\
\text { (6) }\end{array}$ & $\begin{array}{l}\text { Médio } \\
\text { (4) }\end{array}$ & $\begin{array}{l}\text { Médio } \\
\text { (4) }\end{array}$ & $\begin{array}{l}\text { Alto } \\
(6)\end{array}$ & $\begin{array}{l}\text { Médio } \\
\text { (5) }\end{array}$ & $\begin{array}{l}\text { Médio N } \\
\text { (4) }\end{array}$ & $\begin{array}{l}\text { Médio } \\
\text { (4) }\end{array}$ & $\begin{array}{l}\text { Médio } \\
\text { (4) }\end{array}$ & $\begin{array}{l}\text { Baixo } \\
(2)\end{array}$ & $\begin{array}{l}\text { Médio } \\
\text { (4) }\end{array}$ \\
\hline $\begin{array}{l}\text { Função } \\
\text { base } \\
\text { segura }\end{array}$ & $\begin{array}{l}\text { Alto } \\
(6)\end{array}$ & $\begin{array}{l}\text { Alto } \\
\text { (7) }\end{array}$ & $\begin{array}{l}\text { Alto } \\
\text { (6) }\end{array}$ & $\begin{array}{l}\text { Médio } \\
\text { (5) }\end{array}$ & $\begin{array}{l}\text { Médio } \\
\text { (5) }\end{array}$ & $\begin{array}{l}\text { Médio E } \\
\text { (3) }\end{array}$ & $\begin{array}{l}\text { Baixo } \\
\text { (2) }\end{array}$ & $\begin{array}{l}\text { Médio } \\
\text { (3) }\end{array}$ & $\begin{array}{l}\text { Baixo } \\
(1)\end{array}$ & $\begin{array}{l}\text { Médio } \\
\text { (3) }\end{array}$ & $\begin{array}{l}\text { Baixo } \\
\text { (2) }\end{array}$ \\
\hline $\begin{array}{l}\text { Ter } \\
\text { perspect. } \\
\text { do aluno }\end{array}$ & $\begin{array}{l}\text { Alto } \\
(6)\end{array}$ & $\begin{array}{l}\text { Alto } \\
\text { (7) }\end{array}$ & $\begin{array}{l}\text { Alto } \\
\text { (6) }\end{array}$ & $\begin{array}{l}\text { Médio } \\
\text { (5) }\end{array}$ & $\begin{array}{l}\text { Médio } \\
\text { (4) }\end{array}$ & $\begin{array}{l}\text { Médio } \\
\text { (4) }\end{array}$ & $\begin{array}{l}\text { Médio } \\
\text { (4) }\end{array}$ & $\begin{array}{l}\text { Médio } \\
\text { (4) }\end{array}$ & $\begin{array}{l}\text { Médio } \\
\text { (3) }\end{array}$ & $\begin{array}{l}\text { Médio } \\
\text { (5) }\end{array}$ & $\begin{array}{l}\text { Médio } \\
\text { (5) }\end{array}$ \\
\hline $\begin{array}{l}\text { Senso de } \\
\text { eficácia }\end{array}$ & $\begin{array}{l}\text { Alto } \\
\text { (7) }\end{array}$ & $\begin{array}{l}\text { Alto } \\
\text { (7) }\end{array}$ & $\begin{array}{l}\text { Médio } \\
\text { (4) }\end{array}$ & $\begin{array}{l}\text { Alto } \\
(6)\end{array}$ & $\begin{array}{l}\text { Médio } \\
\text { (4) }\end{array}$ & $\begin{array}{l}\text { Baixo } \\
\text { (2) }\end{array}$ & $\begin{array}{l}\text { Médio } \\
\text { (5) }\end{array}$ & $\begin{array}{l}\text { Baixo } \\
(2)\end{array}$ & $\begin{array}{l}\text { Baixo } \\
\text { (2) }\end{array}$ & $\begin{array}{l}\text { Baixo } \\
(2)\end{array}$ & $\begin{array}{l}\text { Baixo } \\
\text { (2) }\end{array}$ \\
\hline $\begin{array}{l}\text { Expressão } \\
\text { afeto } \\
\text { positivo }\end{array}$ & $\begin{array}{l}\text { Alto } \\
(6)\end{array}$ & $\begin{array}{l}\text { Alto } \\
(6)\end{array}$ & $\begin{array}{l}\text { Médio } \\
\text { (4) }\end{array}$ & $\begin{array}{l}\text { Médio } \\
\text { (4) }\end{array}$ & $\begin{array}{l}\text { Médio } \\
\text { (4) }\end{array}$ & $\begin{array}{l}\text { Baixo } \\
\text { (3) }\end{array}$ & $\begin{array}{l}\text { Baixo } \\
\text { (2) }\end{array}$ & $\begin{array}{l}\text { Baixo } \\
(2)\end{array}$ & $\begin{array}{l}\text { Baixo } \\
\text { (1) }\end{array}$ & $\begin{array}{l}\text { Baixo } \\
\text { (2) }\end{array}$ & $\begin{array}{l}\text { Baixo } \\
\text { (2) }\end{array}$ \\
\hline $\begin{array}{l}\text { Neutrali- } \\
\text { dade } \\
\text { afeto } \\
\text { negat. }\end{array}$ & $\begin{array}{l}\text { Médio } \\
\text { (4) }\end{array}$ & $\begin{array}{l}\text { Baixo } \\
\text { (1) }\end{array}$ & $\begin{array}{l}\text { Médio } \\
\text { (4) }\end{array}$ & $\begin{array}{l}\text { Baixo } \\
\text { (2) }\end{array}$ & $\begin{array}{l}\text { Médio } \\
\text { (4) }\end{array}$ & $\begin{array}{l}\text { Baixo } \\
(2)\end{array}$ & $\begin{array}{l}\text { Médio } \\
\text { (4) }\end{array}$ & $\begin{array}{l}\text { Baixo } \\
(2)\end{array}$ & $\begin{array}{l}\text { Baixo } \\
\text { (2) }\end{array}$ & $\begin{array}{l}\text { Baixo } \\
(2)\end{array}$ & $\begin{array}{l}\text { Médio } \\
\text { (3) }\end{array}$ \\
\hline $\begin{array}{l}\text { Desam- } \\
\text { paro } \\
\text { Baixo } \\
\end{array}$ & $\begin{array}{l}\text { Baixo } \\
(2)\end{array}$ & $\begin{array}{l}\text { Baixo } \\
\text { (2) }\end{array}$ & $\begin{array}{l}\text { Médio } \\
\text { (3) }\end{array}$ & $\begin{array}{l}\text { Médio } \\
\text { (4) }\end{array}$ & $\begin{array}{l}\text { Médio } \\
\text { (5) }\end{array}$ & $\begin{array}{l}\text { Alto } \\
(6)\end{array}$ & $\begin{array}{l}\text { Baixo } \\
\text { (2) }\end{array}$ & $\begin{array}{l}\text { Alto } \\
\text { (7) }\end{array}$ & $\begin{array}{l}\text { Alto } \\
(6)\end{array}$ & $\begin{array}{l}\text { Alto } \\
\text { (7) }\end{array}$ & $\begin{array}{l}\text { Alto } \\
\text { (6) }\end{array}$ \\
\hline $\begin{array}{l}\text { Expressão } \\
\text { de raiva/ } \\
\text { hostilidade }\end{array}$ & $\begin{array}{l}\text { Baixo } \\
\text { (1) }\end{array}$ & $\begin{array}{l}\text { Baixo } \\
\text { (1) }\end{array}$ & $\begin{array}{l}\text { Médio } \\
\text { (4) }\end{array}$ & $\begin{array}{l}\text { Baixo } \\
\text { (2) }\end{array}$ & $\begin{array}{l}\text { Baixo } \\
(2)\end{array}$ & $\begin{array}{l}\text { Médio } \\
\text { (5) }\end{array}$ & $\begin{array}{l}\text { Baixo } \\
(2)\end{array}$ & $\begin{array}{l}\text { Alto } \\
\text { (7) }\end{array}$ & $\begin{array}{l}\text { Alto } \\
(6)\end{array}$ & $\begin{array}{l}\text { Médio } \\
\text { (3) }\end{array}$ & $\begin{array}{l}\text { Alto } \\
\text { (6) }\end{array}$ \\
\hline
\end{tabular}

Com base nas pontuações obtidas nas oito escalas, os professores foram distribuídos em três grupos. O primeiro grupo, formado pelos professores dos alunos 7 e 8, obteve alta pontuação para as dimensões positivas e baixa pontuação para as dimensões negativas. O segundo grupo foi composto pelos professores dos alunos 2, 3 e 10, que obtiveram escores altos e médios para as dimensões positivas. A professora do aluno 2 obteve pontuação média para as 3 dimensões negativas; já a professora do aluno 10 obteve pontuações médias para duas dimensões negativas e baixa pontuação para a terceira dimensão. A professora do aluno 3 obteve pontuação média para uma dimensão negativa e pontuações baixas para as demais.

O terceiro grupo, que compreende as professoras dos alunos 9, 1, 11, 6, 5 e 4, obteve pontuação média e baixa para as dimensões positivas, enquanto a pontuação das dimensões negativas mostrou-se variada.

Serão descritas, a seguir, as características das respostas associadas às pontuações altas das escalas positivas e às pontuações baixas das negativas.

Na escala de sensibilidade para disciplina, os professores 7, 8 e 10 obtiveram altas pontuações, enquanto os professores das crianças 1, 2, 3, 6, 9, e 11 obtiveram pontuações médias. 
As altas pontuações nesta escala indicam que os professores relatavam ter regras e expectativas em relação aos alunos, que são comunicadas de forma clara e consistente. Em geral, as regras são dirigidas para encorajar o aluno a obter o máximo de proveito das oportunidades de aprendizagem. Verifica-se o relato de ações pró-ativas que previnem situações indesejadas, como elogiar os comportamentos positivos do estudante ou lembrá-lo das regras e de como agir pró-ativamente diante de situações que poderiam resultar na infração das regras. Os professores demonstram senso de justiça e de disciplina na sala de aula; no entanto, parecem ser capazes de abrir exceções para as regras diante de circunstâncias especiais ou das características individuais do estudante. Relatam tentativas de ajudar o estudante a aprender com os conflitos, e, em relação a comportamentos inapropriados, os professores usam as estratégias de conversar, explicar as conseqüências das ações, verificar a intenção e as estratégias mais adequadas para lidar com a situação, ou seja, apresentam as razões dadas para as regras e expectativas.

Quanto à dimensão função como base segura, os professores 2,7 e 8 obtiveram altas pontuações, enquanto os professores 1, 3, 5, 9 e 10 obtiveram pontuações médias.

As altas pontuações indicam capacidade de expressão e entendimento de que seu apoio emocional está vinculado às competências sociais, emocionais e cognitivas do aluno, seja por meio de manifestações de suas crenças ou de exemplos de comportamentos. Eles descrevem a si mesmos ou a relação com o aluno de maneira a refletir base segura. Apresentam descrições de que fornecem segurança emocional aos alunos e relacionam esta ao desenvolvimento social, emocional e cognitivo desses alunos. Fornecem exemplos claros de que foram bem sucedidos em funcionarem com base segura para o estudante e descrevem episódios nos quais os estudantes foram confortados pela relação estabelecida, além de esclarecer a importância da relação professor-aluno para seu desenvolvimento e estabilidade. Os professores freqüentemente citaram comportamentos que confortam o estudante e expressaram a crença de que os sentimentos são livres para serem discutidos e manejáveis dentro da relação com o aluno, descrevendo sua relação com os alunos como calorosa e próxima.

Em relação à dimensão tomar a perspectiva do aluno, os professores 2, 7 e 8 obtiveram altas pontuações, e os professores 1, 3, 4, 5, 6, 9 e 10 obtiveram médias pontuações. As altas pontuações indicam que os professores demonstram conhecimento dos estados internos de seus alunos e são capazes de se colocar nos lugar deles, esforçam-se para entender o estudante a partir da perspectiva dele e apresentam razões para a experiência vivida pelo aluno. Tais professores evitam rótulos superficiais dados ao aluno e parecem compreender como ele vê o mundo, além de levar em conta o que conhecem sobre ele, suas experiências e qualidades. O professor vê o aluno como possuidor de pensamentos e sentimentos próprios e consegue descrever razões subjacentes a estes.

Quanto ao senso de eficácia, os professores 3, 7 e 8 obtiveram altas pontuações. Esses professores deixam claro que têm intenção de modificar o comportamento do estudante e que são eficazes em seu trabalho de ensinar. Relacionam claramente seus comportamentos às respostas dadas pelo aluno, relatam episódios de situações nas quais suas ações foram associadas aos comportamentos-alvo e relacionam sua intenção com a resposta resultante dada pelo aluno. Os professores tendem a descrever a competência do estudante como relacionada às oportunidades oferecidas a ele em sala de aula e a adaptar suas ações às características do aluno. Em relação à dimensão expressão de afeto positivo, os professores 7 e 8 obtiveram pontuações altas, enquanto os professores 2, 3 , 9 e 10 obtiveram pontuações médias.

As altas pontuações indicam que expressaram sentimentos positivos quanto a sua relação com os alunos (alegria, proximidade, orgulho, carinho, etc.). Manifestam que apreciam ser 
professores daquele aluno e que são apoiadores e amigáveis em sua relação com ele. Fornecem exemplos que incluem afeição física, abraços e proximidade afetuosa.

São apresentados, a seguir, os resultados referentes às três dimensões negativas do instrumento, em que a alta pontuação remete à presença desse construto negativo na relação e a baixa pontuação é associada à existência de elementos desejáveis nela presentes.

Quanto à dimensão neutralização do afeto negativo, foram observadas pontuações baixas e médias.

As pontuações baixas indicam que os professores não neutralizam esse afeto, não se distanciam ou evitam os afetos negativos, ou seja, têm facilidade para lidar com os conteúdos desagradáveis da relação entre ele e o aluno. Eles admitem as emoções negativas e chegam a discuti-las de forma confortável. Já os professores 1, 2, 4, 7 e 10 apresentam pontuações médias, o que significa que conhecem o afeto negativo, mas parecem se recusar a lidar com ele. As respostas dadas podem remeter ao reconhecimento do afeto negativo, mas este é exposto de forma incompleta e distanciada. As pontuações altas remetem aos professores que se esforçam bastante para se distanciar dos afetos negativos, mostram-se relutantes na descrição de discussões e negam os sentimentos negativos. Em geral, esses professores não se sentem confortáveis e mostram-se pouco colaborativos para se referirem a emoções negativas.

Os professores 9, 11, 6, 5 e 4 obtiveram altas pontuações na dimensão desamparo, que avalia os sentimentos de desesperança e ineficiência do professor. No geral, tais sentimentos foram transmitidos. Eles relatam minuciosamente eventos nos quais não foram capazes de influenciar positivamente o comportamento ou desempenho do aluno, ou claramente indicam que não tinham idéia de como poderiam ajudá-lo. Relatam, no geral, sentimento de tristeza por sua falta de eficácia, frustração, falta de esperança, confusão e desapontamento pela falta de progresso do aluno ou pela falta de responsividade deste frente à intervenção do professor. Eles tendem a não usar novas estratégias para favorecer o desempenho do aluno devido a esses sentimentos.

Já os professores 2, 3 e 10 obtiveram pontuações médias nessa escala. Eles relatam que eventualmente são inseguros quanto às influências exercidas sobre seus alunos, ou que não sabem se estão atendendo as necessidades destes. Os professores podem relatar que suas estratégias para promover mudanças no estudante foram efetivas, mas também se referem a ocasiões em que seus esforços não foram bem sucedidos ou até ineficientes.

Na dimensão raiva e hostilidade, os professores 2, 9 e 5 obtiveram pontuações médias, enquanto os professores 4, 6 e 11 obtiveram pontuações altas. As pontuações médias indicam que se referem mais vagamente aos sentimentos de raiva ou hostilidade. Embora expressem alguma raiva, eles não se ocupam desses sentimentos ao longo da entrevista. Os sentimentos de raiva e hostilidade aparecem menos fortes e podem ser vistos com frustração, e não causam impacto na sua relação com o aluno. Eles relatam sentimentos de aborrecimento, raiva ou hostilidade ligados a incidentes particulares (comportamento inadequado, falta de comunicação).

As pontuações altas nessa dimensão indicam expressões diretas de raiva e hostilidade. Os professores manifestam esses sentimentos em direção ao estudante mesmo nas respostas às questões neutras da entrevista, como, por exemplo, na questão em que se solicita ao professor que apresente adjetivos para caracterizar a sua relação com aquele aluno. Quando focados na raiva ou na hostilidade, podem relatar que se sentem desafiados em sua estabilidade emocional. Os professores tendem a transmitir sentimentos de censura, a culpar o aluno e a desaprovar seus esforços, além de usar palavras pejorativas para descrevê-lo. Ao longo da entrevista, esses sentimentos de raiva e hostilidade parecem se manter. 
Slavin (2006)

argumenta

a favor da

tendência

observada entre

os pesquisadores

que vêm

trabalhando com

crianças em fase

de escolarização

de substituírem o

termo "fator de

risco" pelo termo

"colocado em

risco".

\section{Discussões}

O acompanhamento da amostra de 11 alunos destacou que, para $36 \%$ deles, não mais se mantinha a queixa de agressividade indicada há dois anos. No entanto, essa queixa permanece ao final da pré-escola em $45 \%$ dos alunos, além de que, para $18 \%$, a mesma se refere a problemas internalizantes (como introversão/ retraimento e ansiedade/depressão).

Pode-se considerar que, em geral, foram coincidentes as indicações da ausência e da presença de queixas escolares feitas pelas professoras e as classificações limítrofes e clínicas para as categorias de problemas de comportamento avaliadas pelo TRF.

Para os dois casos, o problema de comportamento foi evidenciado somente na entrevista. Para ambos, pode ser possível que tenha ocorrido a continuidade de uma reputação pré-estabelecida, como descrevem os estudos de Leary e Katz (2005). Observa-se que esses mesmos dois alunos, segundo os professores, apresentam adaptação escolar satisfatória, com cumprimento das exigências acadêmicas da pré-escola e motivação para estas; pode-se considerar, portanto, que apresentam condições para enfrentar os desafios previstos para o início do processo formal de escolarização.

Em outros dois casos, a ausência de indicações de problemas é observada tanto na entrevista quanto no TRF.

Verificou-se que, para os sete demais alunos, ocorreu uma coincidência entre as informações do TRF e as queixas apresentadas na entrevista. O uso do TRF mostrou-se útil no sentido de precisar as queixas apresentadas pelas professoras, o que possibilita a identificação do grau de intensidade e gravidade dos problemas comportamentais descritos bem como a de indicação de comorbidade de problemas.

Desse grupo de sete alunos, somente dois apresentam aproveitamento acadêmico e motivação escolar considerados pelos professores como satisfatórios. Além disso, apenas uma outra criança desse grupo, segundo a professora, tem relações satisfatórias com colegas. Pode-se verificar que, em termos comportamentais, sociais e acadêmicos, a adaptação desses alunos na fase final da préescola se mostra comprometida.

\section{Considerações finais}

Os resultados do presente estudo apóiam as evidências da literatura de que comportamentos agressivos tendem a se manter ao longo do tempo (Coie \& Dodge, 1998; Patterson et al., 1989) e que intervenções planejadas e consistentes, focadas na família e na escola, são necessárias para a superação e a não intensificação dos problemas comportamentais de alunos no final da primeira infância (WebsterStratton, 1998; Webster-Stratton \& Reid, 2004).

A maioria das crianças estudadas está exposta a fatores de risco e parece não apresentar rede protetora suficiente para minimizar esses efeitos.

A discussão conceitual recente sobre o termo fator de risco pode ser aplicada às questões levantadas neste estudo. Slavin (2006) argumenta a favor da tendência observada entre os pesquisadores que vêm trabalhando com crianças em fase de escolarização de substituírem o termo "fator de risco" pelo termo "colocado em risco". O principal argumento apresentado é que "colocado em risco" enfatiza o fato de que, em geral, são respostas inadequadas dadas às necessidades da criança por parte da escola, da família ou da comunidade que a expõem a riscos. Por exemplo, uma criança poderia ser bem sucedida em leitura se ela tivesse um ensino apropriado ou usar óculos. Se, no entanto, faltam esses serviços ou recursos, pode-se considerar que ela está sendo colocada em risco.

Essa nova maneira de interpretar as experiências negativas ou estressantes das crianças considera que, antes da entrada na escola, os fatores de risco mais preditivos são os relacionados ao status socioeconômico e à estrutura familiar. No entanto, depois que a criança entra no 
processo de escolarização, os fatores de risco, tais como o desempenho acadêmico, a repetição de série, o comportamento e o ajustamento comprometidos se tornam os preditores mais relevantes para o surgimento de problemas escolares posteriores do que os fatores relacionados ao histórico familiar (Slavin, 2006).

Os resultados do presente estudo evidenciam a importância do desenvolvimento de estudos de acompanhamento da adaptação de alunos de risco ao contexto pré-escolar bem como de ampliar esse acompanhamento para os níveis de ensino posteriores. A verificação de que uma parcela dos alunos já entra no ensino fundamental apresentando acentuadas dificuldades comportamentais e insuficiente domínio dos pré-requisitos acadêmicos está de acordo com os resultados da literatura a respeito do desenvolvimento e do difícil manejo desses comportamentos (Gomide, 2001, 2003; Marinho, 2003; Patterson et al., 2002; Patterson et al., 1989). Considera-se que essa constatação poderia ser considerada nos estudos que exploram as relações entre dificuldades de aprendizagem no ensino fundamental e exibição de problemas de comportamento.

Os resultados relativos às percepções das professoras sobre como se dá a relação com um aluno específico da amostra indicam que pelo menos dois deles já estabelecem relações professor-aluno desejáveis, caracterizadas por elementos básicos exigidos, que remetem ao apoio socio-emocional fornecido a esses alunos. Os resultados referentes aos demais professores demonstram a necessidade de aprimoramento da qualidade da relação estabelecida com os alunos. Ressalta-se que não só o apoio fornecido pelo professor é importante para minimizar os comportamentos agressivos de pré-escolares; a literatura incentiva os esforços em conjunto tomados pela família e pela escola para minimizarem esses problemas. Além disto, aponta a importância da presença do psicólogo no acompanhamento desses casos, para que seja viabilizada a orientação tanto aos pais quanto à escola, ao mesmo tempo em que oferece o atendimento especializado às necessidades da criança (Webster-Stratton, 1998; Webster-Stratton \& Reid, 2004).

Este estudo buscou focalizar a importância do professor como agente ativo na prevenção e na diminuição desses problemas e descrever características favoráveis da relação que podem beneficiar o aluno. Atualmente, existem programas especificamente elaborados para desenvolver e aprimorar habilidades em professores de pré-escolares em situação de risco. Dentre estes, destaca-se a proposta de capacitação para professores, de Luizzi e De Rose (2007), que visa à prevenção de comportamentos agressivos em pré-escolares. Este estudo traz uma revisão de programas de intervenção escolar bem-sucedidos e a apresentação de um programa adaptado à realidade nacional, que visa a promover o aprimoramento das habilidades de professores no sentido de prevenir ou minimizar a apresentação de comportamentos agressivos em alunos de pré-escola.

Também pode ser citado o trabalho de capacitação de professores, desenvolvido e aplicado através da internet, de Kinzie et al. (2006), que poderia ser adaptado à realidade nacional.

Para a maioria dos alunos da presente pesquisa, seria importante ter oportunidades de estímulo, para que fossem desenvolvidas habilidades sociais, emocionais e acadêmicas básicas, como melhoria da comunicação, cooperação, engajamento ativo e atenção nas tarefas, como aponta Webster-Stratton (1998). A efetividade dessas oportunidades depende em parte da qualidade ou do tom presente na relação professor-aluno. Nesse sentido, os alunos da amostra poderiam ser beneficiados em termos de desenvolvimento de habilidades e de apoio socioemocional se contassem com o estabelecimento de uma relação com professores que funcionasse como base segura e enfatizasse um tom afetivo positivo, como afirmam Hamre e Pianta (2005).

Pode-se considerar que o uso da entrevista proposta por Pianta (1998) para a caracterização 
das dimensões positivas e negativas associadas ao apoio emocional e afetivo dos alunos em situação de risco mostrou-se útil e promissor. Verificou-se a sensibilidade do instrumento para indicar as variações nos relatos dos professores no que diz respeito às dimensões apresentadas.

Os resultados fornecidos podem ser considerados como subsídios precisos para nortear um trabalho de melhoria da relação professor-aluno, tendo em vista a importância desta como integrante de um conjunto de ações a serem tomadas frente a problemas de comportamento agressivo em pré-escolares. Destaca-se a importância de estudos que envolvam intervenções junto aos professores dirigidas ao aprimoramento do conjunto das oito dimensões da relação professor-aluno apontadas por Pianta (1998), e, em conseqüência, ao fortalecimento do apoio emocional e afetivo oferecido aos alunos em situação de risco.

\section{Juliana da Rocha Picado*}

Psicóloga e Mestre em Educação Especial pela Universidade Federal de São Carlos, UFSCar.

\section{Tânia Maria Santana de Rose}

Doutora em Psicologia Experimental - USP. Docente do Programa de Pós-Graduação em Educação Especial da Universidade Federal de São Carlos.

\section{*Endereço para envio de correspondência:}

Rua Eliseu Guilherme, 506 - Sumaré. Cep: 14025-020, Ribeirão Preto-SP

E-mail: jupicado@gmail.com

Recebido 04/03/2008; Reformulado 18/09/2008; Aprovado 25/09/2008.

Referências
Achenbach, T. M. (1991). Integrative guide for the $1991 \mathrm{CBCL} / 4-18$ YSR, and TRF profiles. Burlington: Departament of Psychiatry, University of Vermont-USA.

Birch, S. H., \& Ladd, G. W. (1997). The teacher-child relationship and children's early school adjustment. Journal of School Psychology, 35(1), 61-79.

Coie, J. D. \& Dodge, K. A. (1998). Agression and antisocial behavior. In W. Damon \& N. Einsberg (Eds.), Handbook of child psychology. Vol. 3: Social emotional and personality development (5th ed., pp. 779-862). New York: John Wiley and Sons.

Del Prette, A., \& Del Prette, Z. A. P. (2001). Psicologia das relações interpessoais: vivências para o trabalho em grupo (2a ed.). Petrópolis, RJ: Vozes.

De Rose, T. M. S., Coser, D. S., \& Togumi, A. (2004). Mecanismos de proteção e de vulnerabilidade presentes no contexto escolar de um grupo de alunos que vivem em situação de pobreza. In XII Congresso de Iniciação Científica da UFSCar. São Carlos, SP.

Gomide, P. I. C. (2001). Efeitos das práticas educativas no desenvolvimento do comportamento anti-social. In M. L. Marinho \& V. E. Caballo (Orgs.), Psicologia clínica e da saúde (pp. 33-53). Londrina, PR: UEL.

Gomide, P. I. C. (2003). Estilos parentais e comportamento antisocial. In A. Del Prette \& Z. Del Prette (Orgs.), Habilidades sociais, desenvolvimento e aprendizagem: questões conceituais, avaliação e intervenção (pp. 21-60). Campinas, SP: Alínea.

Hamre, B. K., \& Pianta, R. C. (2005). Can instructional and emotional support in the first-grade classroom make a difference for children at risk of school failure? Child Development, 76(5), 949-967.

Kinzie, M. B., Whitaker, S. D., Neesen, K., Kelley, M., Matera, M., \& Pianta, R. C. (2006). Innovative web-based professional development for teachers of at-risk preschool children. Educational Technology \& Society, 9(4), 194-204.

Leary, A., \& Katz, L. F. (2005). Observations of aggressive children during peer provocation and with a best friend. Development Psychology, 41(1), 124-134.

López, F. (2004). Problemas afetivos e de conduta na sala de aula. In C. Coll, A. Marchesi \& J. Palacios (Orgs.), Desenvolvimento psicológico e educação: transtornos do desenvolvimento e neces- sidades educativas especiais (pp. 113-128). Porto Alegre: Artmed.

Luizzi, L., \& De Rose, T. M. S. (2003). Comportamento agressivo em pré-escolares: incidência e fatores de risco. In Anais da XXXIII Reunião Anual da Sociedade Brasileira de Psicologia (pp. 77-178). Belo Horizonte: SBP.

Luizzi, L., \& De Rose, T. M. S. (2007). Prevenção de comportamentos agressivos entre pré-escolares: uma proposta de capacitação para professores. Dissertação de Mestrado em Educação Espeçial, Universidade Federal de São Carlos, São Carlos, SP.

Marinho, M. L. (2003). Comportamento anti-social infantil: questões teóricas e de pesquisa. In A. Del Prette \& Z. A. P. Del Prette (Orgs.), Habilidades sociais, desenvolvimento e aprendizagem: questões conceituais, avaliação e intervenção (pp. 61-81). Campinas, SP: Alínea.

Patterson, G. R., Debaryshe, B. D. \& Ramsey, E. (1989). A developmental perspective on antisocial behavior. American Psychologist, 44(2), 329-335.

Patterson, G. R., Reid, J., \& Dishion, T. (2002). Antisocial boys (A. C. Lima \& G. V. M. Rocha, trads.). Santo André, SP: ESETec.

Pianta, R. C. (1998). Enhancing relationships between children and teachers. Washington, DC: American Psychological Association.

Pianta, R. C., \& Walsh, D. J. (1996). High-risk children in schools: Constructing sustaining relationships. New York: Rutledge.

Slavin, R. E. (2006). Educational psychology: Theory and practice (8th ed.). Boston: Pearson.

Tremblay, R. E. (2000). The development of aggressive behavior during childhood: What have we learned in the past century? International Journal of Behavioral Development, 24(2), 129-141.

Webster-Stratton, C. (1998). Preventing conduct problems in head start children: Strengthening parenting competencies. Journal of Consulting and Clinical Psychology, 5, 715-730.

Webster-Stratton, C., \& Reid, M. J. (2004). Strengthening social and emocional competence in young children - the foundation for early school readiness and sucess. Infants and Young Children, $17(2), 96-113$. 